\title{
Dynamic effect of metro-induced vibration on the rammed earth base of the Bell Tower
}

\author{
Jinxing Lai ${ }^{1}$, Fangyuan Niu ${ }^{1}$, Ke Wang ${ }^{1,2^{*}}$, Jianxun Chen ${ }^{1}$, Junling Qiu ${ }^{1 *}$, Haobo Fan ${ }^{1}$ and Zhinan $\mathrm{Hu}^{3}$
}

*Correspondence:
372836091@qq.com;
870133597@qq.com
${ }^{1}$ School of Highway,
Chang'an University,
Xi'an 710064, China
Full list of author information
is available at the end of the
article

*Correspondence: 372836091@qq.com 870133597@qq.com 1 School of Highway, Chang'an University Full list of author information article

\begin{abstract}
Xi'an Bell Tower (the Bell Tower) is a state-level ancient relic in China. The vibration caused by metro will exert adverse effect on the Bell Tower. This paper aims at presenting 3D-FEM models to predict the peak period velocity (PPV) of rammed earth base when the metro passing through the Bell Tower. The calculation results are compared with those of field test. Both results were found to be in good agreement. Furthermore, the results indicated that the effect of shock absorption measures is significant. The shock absorption tracks can obviously decrease the vibration of the Bell Tower, and the maximum decrease of PPV of the rammed earth base is $78.91 \%$. The proposed prediction has the potential to be developed as a decision and management tool for the evaluation of the risk associated with the influence of vibration caused by metro on buildings in urban areas.
\end{abstract}

Keywords: Metro vibration, The Bell Tower, FEM, Tunnel, Peak particle velocity (PPV)

\section{Background}

As one of four ancient capitals in the world, Xi'an was once the capital for 13 dynasties in Chinese history. The Bell Tower, as a city landmark, is a precious ancient building with a history of over 600 years, but its durability has been gradually weakened for the long history. Xian is now enjoying a boom in metro construction, which will unavoidably cause vibration for the Bell Tower. In the other word, even the tiniest vibrations may lead to fatigue failure for the Bell Tower since the continuous vibration.

In 1970s to 1990s, some researches analyzed the deformation and failure rules of the ancient structures under the vibration according to field tests (Mata 1971; Rueker 1982; Ellis 1987; Clemente and Rinaldis 1998). At the same tine, some researches on prevention of ancient buildings against transportation vibration are made by some European and American experts (Lang 1971; Dawn and Stanworth 1979; Kurzweil 1979). In addition, some new methods, such as artificial neural networks and numerical simulations, are used to address the vibration features of buildings under seismic wave (Degrande and De Roeck 1998; Degrande and Lombaert 2001; Lombaert et al. 2006; Real et al. 2015; Real 2014; Lai et al. 2014, 2015a, 2016b; Ye et al. 2014; Li et al. 2013; Han and Jia 2015; Han et al. 2014). In recent years, some scholars studied the structural and mechanical characteristics under the vibration energy. For example, Dr. Jia Yingxun et al. studied

(c) 2016 The Author(s). This article is distributed under the terms of the Creative Commons Attribution 4.0 International License (http://creativecommons.org/licenses/by/4.0/), which permits unrestricted use, distribution, and reproduction in any medium, provided you give appropriate credit to the original author(s) and the source, provide a link to the Creative Commons license, and indicate if changes were made. 
the influence of vibration of Beijing Metro Lines 6 and 8 on ancient buildings (Luo et al. 2015; Yu and Fang 2006; Jia et al. 2009; Xie 2008). Research results indicated that the dynamic response of ancient building structure caused by train vibration changed along with the change of horizontal and vertical distances. On the other hand, to better understand and preserve ancient ruins against train-induced vibrations, vibration measurements and FE analysis were conducted on the Hangu Pass, Luoyang, China, located adjacent to the Longhai railway line (Ye et al. 2015), and the results showed that the set isolation trench can protect the ancient ruin against environmental vibration. In order to ensure the safety and stability of subway tunnel in the practical operation of demolition blasting of the viaduct, Zhao et al. (2015) put forward composite protective structures of steel-rubber tires and makes safety checking calculation of the subway tunnel on the basis of composite protective measures by numerical simulation, and the composite protection system was further optimized.

The influence of metro vibration on REB of the Bell Tower was studied in this paper which will provide valuable experience for protecting similar ancient cultural relics. In order to make an evaluation on the stability of the Bell tower, the field investigation was conducted in the paper firstly that can provide soil parameters for finite element model of the Bell Tower and get the soil layer structure and engineering characteristics. What is more, here we summarized a lot of vibration safety standards of buildings, and got the most suitable vibration safety standards for the Bell Tower. Thirdly, 3D-FEM models are made to simulate the working conditions including with or without shock absorption tracks and different train speeds. Finally, the calculation results are compared with field tests for verifying the correctness in the paper.

\section{Overview of the Bell Tower}

As the symbol of Xi'an, the Bell tower was built in Ming dynasty, and was a classical brick-and-wood structure. The tower body was borne by 4 central cylinders and 12 surrounding cylinders, as shown in Fig. 1. The cylinders are connected by beams with the large depth-span ratio (Meng 2009). The Bell Tower was facing a lot of damage though

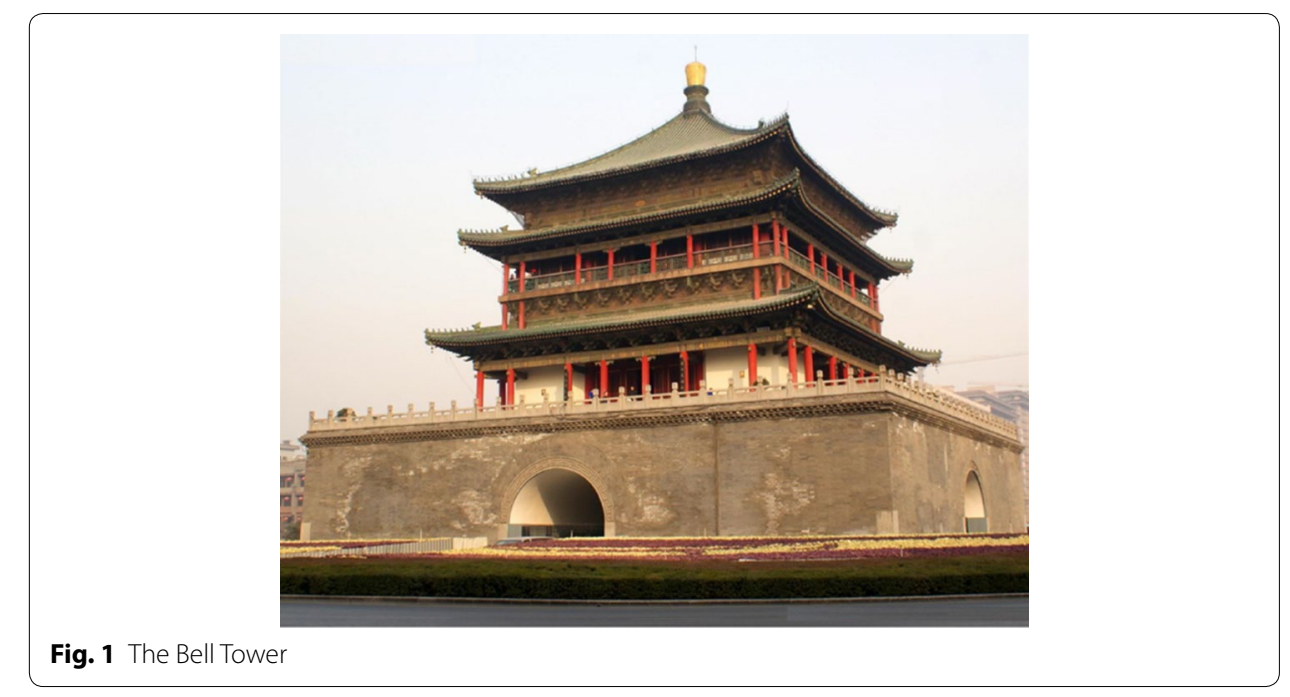


many renovations had been done in history. An evaluation work on the Bell Tower was performed in 2008, and damages were observed as shown in Figs. 2 and 3, and the specific geological survey was shown in Fig. 4 (Chen 2008).

\section{Vibration safety standards}

There are different vibration safety standards in different countries, including America, UK, Germany, Japan, Portugal, Swiss, and China, as shown in Table 1. These standards are greatly different for the different environment and structure. However, the physical parameters for analyzing the influence of vibration on buildings are always vibration speed and frequency which are directly related to the damage degree of structures, and playing a decisive role. The standard "Xi'an City Scheme on Protection of Cultural Relics When Urban Track Rapid Transit Line 2 Goes through Bell Tower and City Wall”, formulated by State Administration of Cultural Heritage, was validated by comparing these vibration standards, namely "the PPV of the Bell Tower and City Wall caused by metro vibration is suggested to be controlled within $0.15-0.2 \mathrm{~mm} / \mathrm{s}$ " (Ma et al. 2016).

Fig. 2 Crack
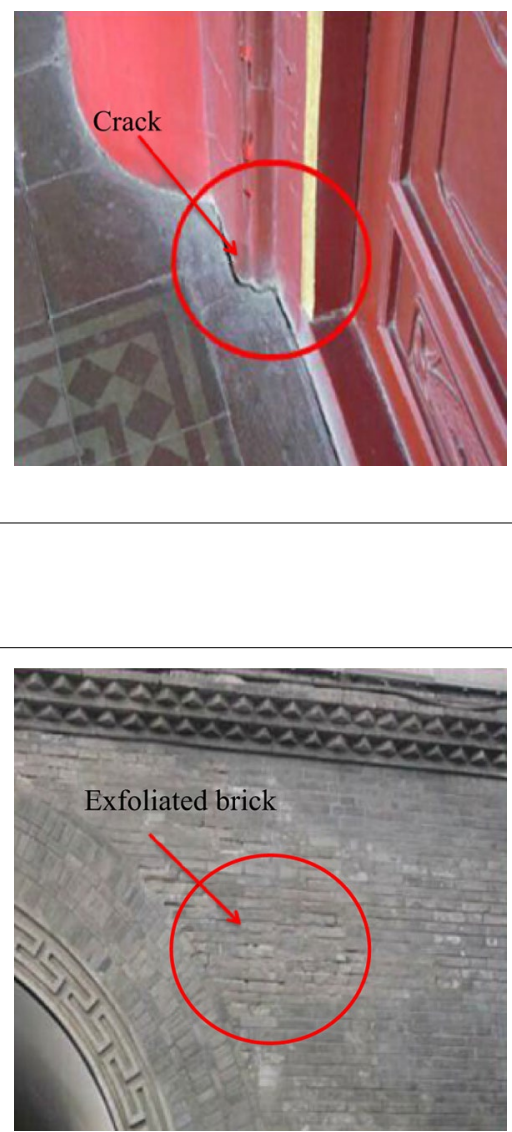

Fig. 3 Exfoliated brick 


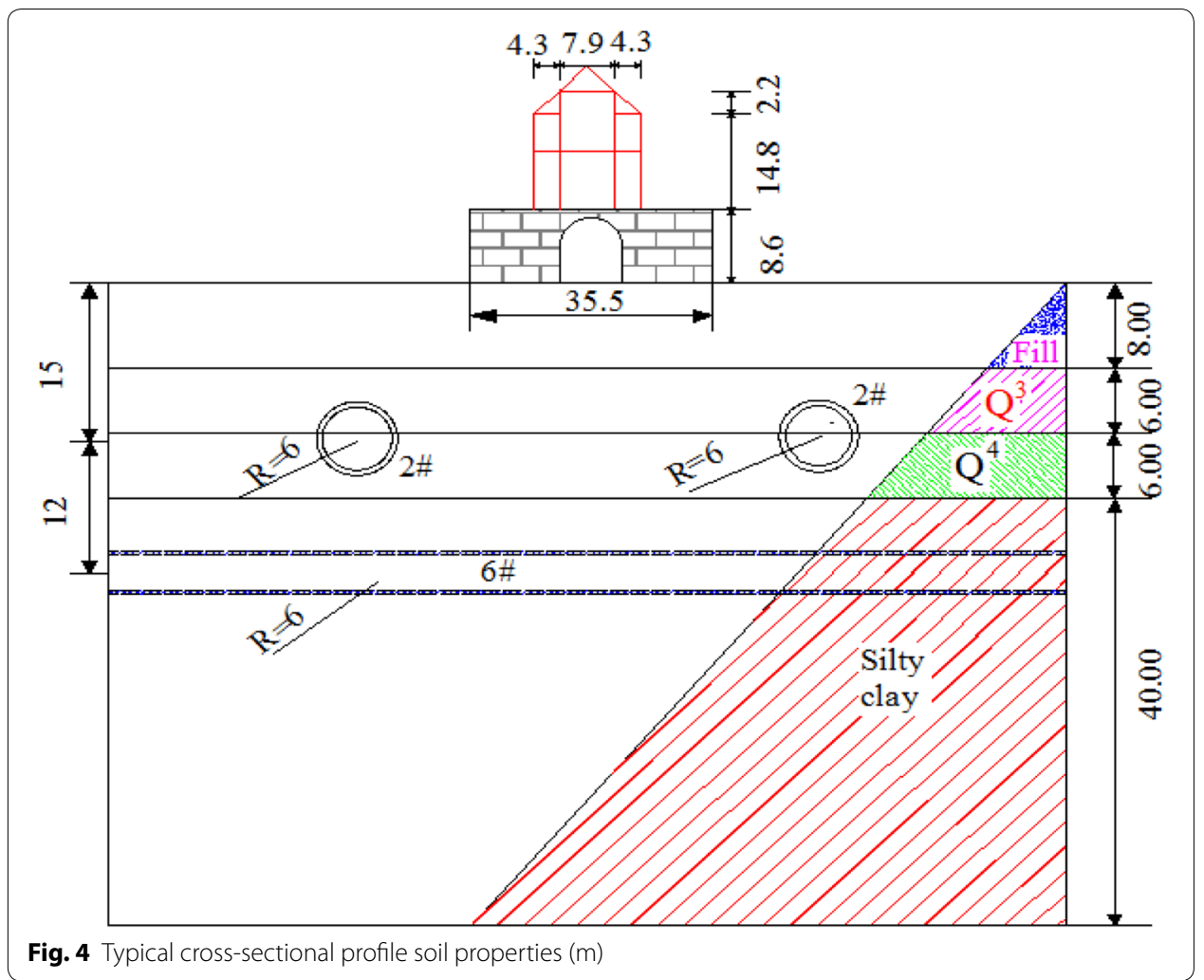

Table 1 Summary of vibration guide values for structure damage

\begin{tabular}{|c|c|c|c|}
\hline Vibration standard & $\begin{array}{l}\text { Evaluating } \\
\text { index }\end{array}$ & Evaluation object & $\begin{array}{l}\text { Evaluation } \\
\text { value }(\mathrm{mm} / \mathrm{s})\end{array}$ \\
\hline ISO 4866:2010 (ISO 2010) & PPV & Ancient architecture & 2.5 \\
\hline $\begin{array}{l}\text { Germany DIN4150-3:1999 (Ger- } \\
\text { many 1999) }\end{array}$ & PPV & Ancient architecture & $3-10$ \\
\hline UK BS7385-2 (UK 1993) & PPV & Ancient architecture & 7.5 \\
\hline $\begin{array}{l}\text { Switzerland 6.10SN640312:1992 } \\
\text { (Swiss 1992) }\end{array}$ & PPV & Old and poorly maintained buildings & 2 \\
\hline Portugal (Meng 2009) & PPV & Ancient architecture & 2.5 \\
\hline Japan (Cao 2006) & PPV & Ancient architecture & 5 \\
\hline China GB10070-88 (China 2003) & PPV & $\begin{array}{l}\text { Ancient architecture (cracking and } \\
\text { weathering) }\end{array}$ & $1.8-3.0$ \\
\hline $\begin{array}{l}\text { China GB/T50452:2008 (China } \\
\text { 2008) }\end{array}$ & PPV & Ancient architecture & $3-5$ \\
\hline $\begin{array}{l}\text { State Administration of Cultural } \\
\text { Heritage (Meng 2009) }\end{array}$ & PPV & The Bell Tower and the City Wall & $0.15-0.2$ \\
\hline
\end{tabular}

\section{Numerical analysis}

\section{Research content}

There are two metro lines under the Bell Tower, Metro Lines 2 and 6 (2\# and 6\#, Fig. 4). There were six combinations of the Metro Lines in the finite element model (Table 2), and the train speed was $20,40,60$ and $80 \mathrm{~km} / \mathrm{s}$ for each combination. 
Table 2 Six combinations

\begin{tabular}{llll}
\hline Condition & Track type & Metro combination & Train amount \\
\hline 1 & Conventional track & $2 \#+6 \#$ & 4 \\
2 & Conventional track & $2 \#+2 \#$ & 2 \\
3 & Conventional track & $6 \#+6 \#$ & 2 \\
4 & Shock absorption track & $2 \#+6 \#$ & 4 \\
5 & Shock absorption track & $2 \#+2 \#$ & 2 \\
6 & Shock absorption track & $6 \#+6 \#$ & 2 \\
\hline
\end{tabular}

\section{Numerical model}

In this study, 3D-FEM models to predict the influence of Metro Lines 2 and 6 on the Bell Tower were presented by MIDAS/NX (MIDAS Co., Ltd) (Fig. 5). The conventional, masonry structure, soil layers and shock absorption tracks were defined as solid element, tunnel lining was defined as shell element, jet grouting piles under the masonry structure were defined as plate element, wooden beams and columns were defined as beam element, and steel springs on floating slab of shock absorption tracks were defined as elastic connection element (whose rigidity are $6900 \mathrm{kN} / \mathrm{m}$, spacing is $1.2 \mathrm{~m}$ ) (Meng

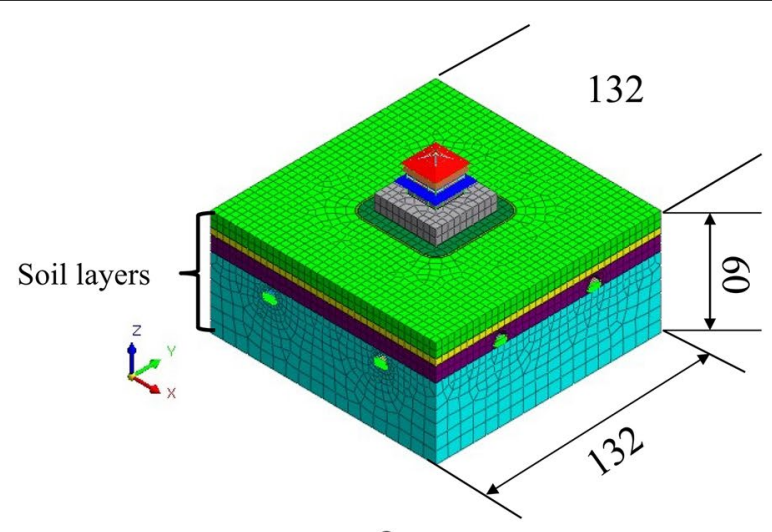

a

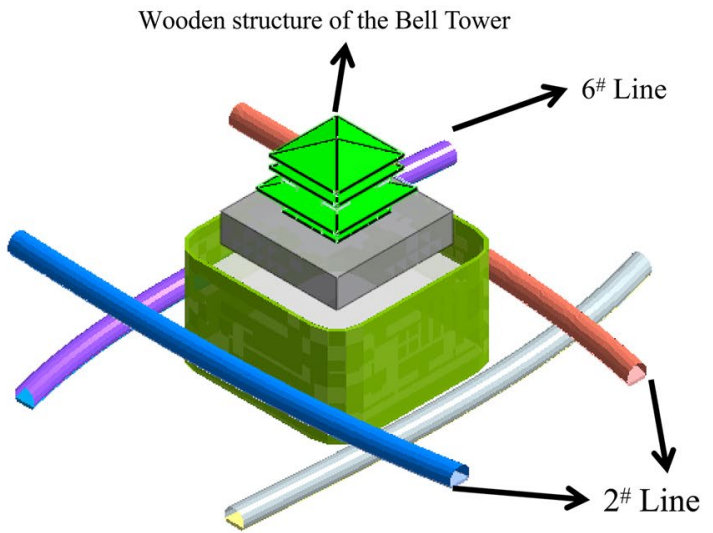

b

Fig. 5 Mesh model (m). a Model size, b Tunnel location 
2009). The model soil was simplified to four layers, and the model soil parameters were shown in Table 3 (Chen 2008), the other model parameters were shown in Table 4.

\section{The time period and time increment size}

According to different sampling frequency, the time period and time increment size of the environmental vibration problem are studied in many Literatures (Ma et al. 2016; Lai et al. 2016a, b, c). The research results show that when the minimal time period of the model is 50 times as much as the time increment size, the error of the calculation results can not be considered. The ground time-period of the Bell Tower is $0.29-0.4 \mathrm{~s}$, so when the time increment size is $0.005 \mathrm{~s}$, the computational accuracy meets the requirements.

\section{Dynamic analysis equation}

The motion equation of the structural system based on Hamilton principle (Meng 2009) is:

$$
[M]\{\ddot{u}\}+[C]\{\dot{\ddot{u}}\}+[K]\{u\}=\{F(t)\}
$$

where $[M],[C]$ and $[K]$ are the mass matrix, damping matrix, and stiffness matrix of the system, respectively, and they are combined with the mass matrix, damping matrix, and stiffness matrix of all units together; $\{\ddot{u}\},\{\dot{u}\}$, and $\{u\}$ are the acceleration vector, velocity vector and displacement vector of the system, respectively; $F(t)$ refers to nodal force vector changing along with time. The mass matrix, damping matrix and stiffness matrix as well as nodal force vector are calculated as follows:

$$
\begin{aligned}
& {\left[M_{e}\right]=\iiint \rho[N]^{T}[N] d V} \\
& {\left[C_{e}\right]=\iiint c[N]^{T}[N] d V}
\end{aligned}
$$

Table 3 Numerical model soil parameters

\begin{tabular}{llllll}
\hline Parameter & Unit & Fill & $\mathbf{Q}^{\mathbf{3}}$ & $\mathbf{Q}^{\mathbf{4}}$ & Silty clay \\
\hline Height $(H)$ & $(\mathrm{m})$ & 8 & 3.5 & 8 & 40 \\
Soil Young modulus $(E)$ & $(\mathrm{MPa})$ & 110 & 403 & 495 & 622 \\
Poisson's ratio $(\mathrm{V})$ & $(-)$ & 0.175 & 0.163 & 0.160 & 0.158 \\
Cohesion $(C)$ & $(\mathrm{kPa})$ & 24.3 & 25.3 & 37.5 & 35.5 \\
Angle of internal friction $(\varphi)$ & $\left({ }^{\circ}\right)$ & 12 & 12.5 & 20.2 & 25.2 \\
Soil unit weight $(\gamma)$ & $\left(\mathrm{kg} / \mathrm{m}^{3}\right)$ & 17.8 & 20.4 & 20.2 & 20.6 \\
\hline
\end{tabular}

Table 4 Unit parameters

\begin{tabular}{llllll}
\hline Unit & $\boldsymbol{\rho}\left(\mathbf{g} / \mathbf{c m}^{\mathbf{3}}\right)$ & $\boldsymbol{E}(\mathbf{G p a})$ & $\boldsymbol{v}$ & $\boldsymbol{C}(\mathbf{K p a})$ & $\boldsymbol{\Phi}\left({ }^{(}\right)$ \\
\hline Jet grouting piles & 2.3 & 39 & 0.29 & - & - \\
REB & 1.67 & 3 & 0.3 & 48 & 35 \\
Tunnel lining & 2.5 & 40 & 0.29 & - & - \\
Track & 2.4 & 46 & 0.3 & - & - \\
\hline
\end{tabular}




$$
\begin{aligned}
& {\left[K_{e}\right]=\iiint[B]^{T}[D][B] d V} \\
& {\left[F_{e}\right]=\iiint[N]^{T}\{f\} d V+\iint[N]^{T}[\bar{P}] d B}
\end{aligned}
$$

Generally, it is assumed that the relationship between the damping matrix and mass matrix, stiffness matrix is in direct proportion, that is Rayleigh damping is adopted (Chen 2008), and the expression is as follow:

$$
[C]=\alpha[M]+\beta[K]
$$

According to the orthogonal condition of the vibration mode, the undetermined constants $\alpha$ and $\beta$ and the damping ratio should satisfy the following relationship:

$$
\xi_{k}=\frac{\alpha}{2 \omega_{k}}+\frac{\beta \omega_{k}}{2} \quad(k=1,2, \ldots, n)
$$

where $\xi_{k}$ is the damping ratio; $\omega_{k}$ is the inherent frequency; $\alpha$ and $\beta$ are damping ratio coefficients.

The free vibration equation of the system can be used to calculate the inherent frequency of $\omega_{i}$ and $\omega_{j}$, and based on tests and similar structure data, the damping ratios of $\xi_{i}$ and $\xi_{j}$ can be obtained. From formula (4), $\alpha$ and $\beta$ are obtained. If $\xi_{i}=\xi_{j}, \omega_{0}$ and $\xi_{0}$ is the fundamental frequency of system and the damping ratio of corresponding vibration mode, respectively, then the following relational expression can be obtained:

$$
\left\{\begin{array}{l}
\alpha=\xi_{0} \omega_{0} \\
\beta=\xi_{0} / \omega_{0}
\end{array}\right.
$$

\section{Boundary conditions}

When finite element method is adopted to simulate the vibration, the truncation boundary will generate reflection, which will result in distortion of calculation. To avoid distortion, spring viscous artificial boundary is set in this model (Meng 2009). Viscous artificial boundary not only can simulate the excluded soil and its rigidity in finite element model, but also can avoid the reflection of truncated boundary (MIDAS Co., Ltd). The lecture (Chen 2008) suggests the artificial viscous damping force in two directions along boundary surface, with the magnitude:

$$
\left\{\begin{array}{l}
\bar{\sigma}=a \rho v_{\mathrm{P}} \dot{w} \\
\bar{\tau}=b \rho v_{\mathrm{S}} \dot{u}
\end{array}\right.
$$

where $\bar{\sigma}$ and $\bar{\tau}$ are the normal stress and shear stress along artificial boundary, respectively; $\dot{w}$ and $\dot{u}$ are the velocity component in normal and tangential directions along the boundary, respectively; $v_{P}$ and $v_{S}$ are the velocity of incident pressure wave and shear wave, respectively; and the values of $a$ and $b$ can be found in the lecture [28].

\section{Train load}

The vibration during metro operation is caused by train dynamic load. There are many kinds of trains in MIDAS/NX and it just needs some relevant parameters (MIDAS Co., 
Ltd), including train type, number of wheels, wheel distance, train speed, running distance, etc. The train formation of Xi'an Metro is six trains (Meng 2009). So the standard train EL-18 was adopted in the model (MIDAS Co., Ltd), and the number and separation distance of wheels were shown in Fig. 6. The vibration response of the Bell Tower was simulated at the speed of 20,40,60 and $80 \mathrm{~km} / \mathrm{h}$, respectively. The distance that trains pass through the Bell Tower was $60 \mathrm{~m}$. The dynamic load generated at the speed of $80 \mathrm{~km} / \mathrm{h}$ was shown in Fig. 7.

\section{Numerical results}

A number of numerical simulations have been carried out to investigate the effects of metro vibration to the Bell Tower: (1) the distribution of PPV in REB; (2) the laws of P PV in different condition; (3) the effect of the shock absorption tracks.

\section{The PPV of the REB}

Vibration velocities of the REB in each condition were shown at Figs. 8, 9, 10, 11, 12 and 13. In order to facilitate the analysis, we chose a representative of the four corners of the REB, that is A, B, C, and D. As we can see, the PPV of the corners in each condition changes with the change of train velocity. To the condition 1 and condition 4 , when there are four trains, the maximum PPV is corner D when the train velocity is $20 \mathrm{~km} / \mathrm{h}$, the maximum PPV is corner $C$ when the train velocity is $60 \mathrm{~km} / \mathrm{h}$, and the maximum PPV is corner D when the train velocity is $80 \mathrm{~km} / \mathrm{h}$. The only difference is when the

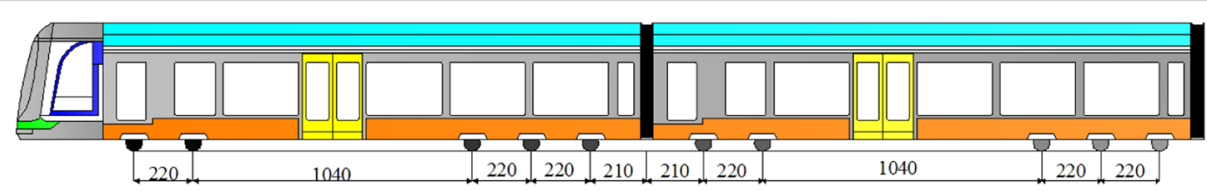

Fig. 6 Two carriages and wheel span (cm)

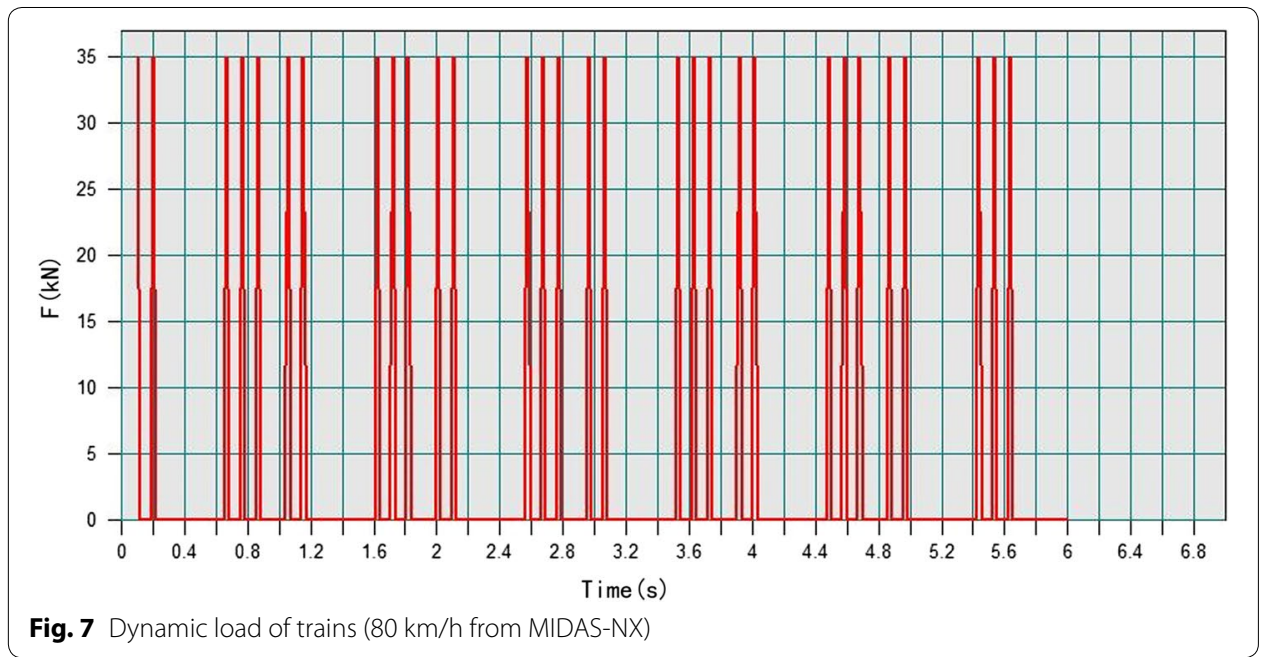




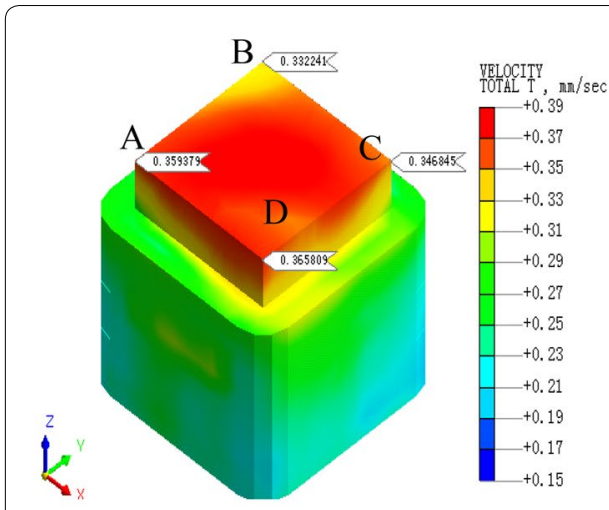

a

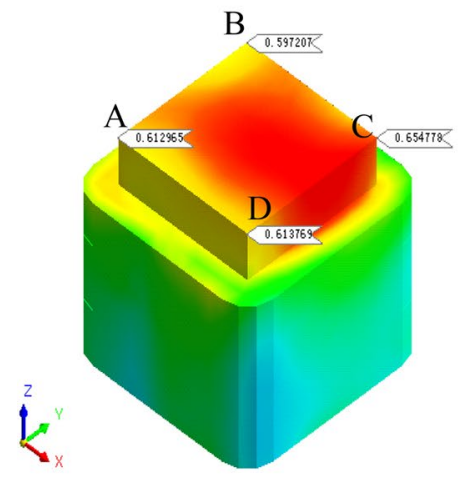

c

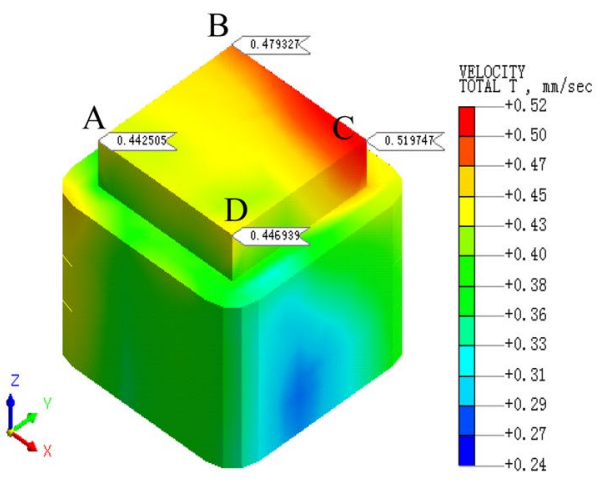

b

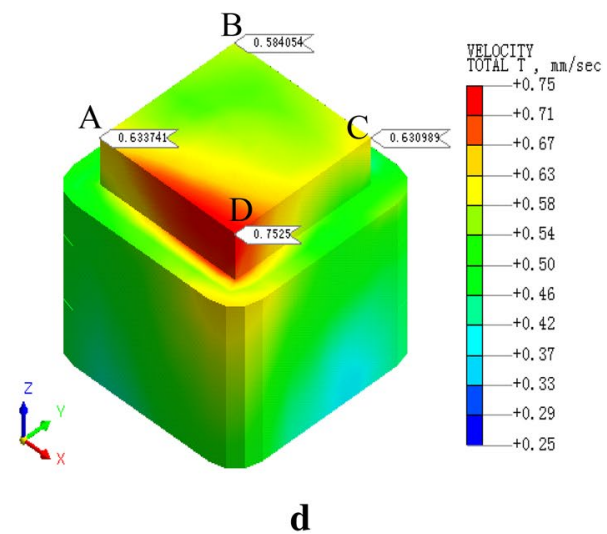

Fig. 8 PPV of the condition 1. a $v=20 \mathrm{~km} / \mathrm{h}, \mathbf{b} v=40 \mathrm{~km} / \mathrm{h}, \mathbf{c} v=60 \mathrm{~km} / \mathrm{h}, \mathbf{d} v=80 \mathrm{~km} / \mathrm{h}$

train velocity is $40 \mathrm{~km} / \mathrm{h}$, where the maximum PPV is corner $C$ in condition 1 but the maximum PPV is corner D in condition 4 . To the other four conditions, there are similar rules, as shown in Table 7. The whole results indicated the PPV of four trains is larger than two trains (Table 5), and the location of the maximum PPV is basically consistent when the train number and velocity are identical. What is more, the maximum PPV of condition 1-3 were beyond standard and the condition 4-6 met standard requirements (Table 6).

\section{Distribution laws of PPV}

As can be seen, (1) According to Figs. 14, 15, 16, 17, 18 and 19, most of the curve showed a rising trend, but some PPV curve decrease as the velocity increase which is consistent with the regularities obtained in previous studies (Zhao et al. 2015). The reasons are that there are many factors will make effect on the vibration frequency the REB, such as track category, train quantity and the running mode of train. (2) When there were no shock 


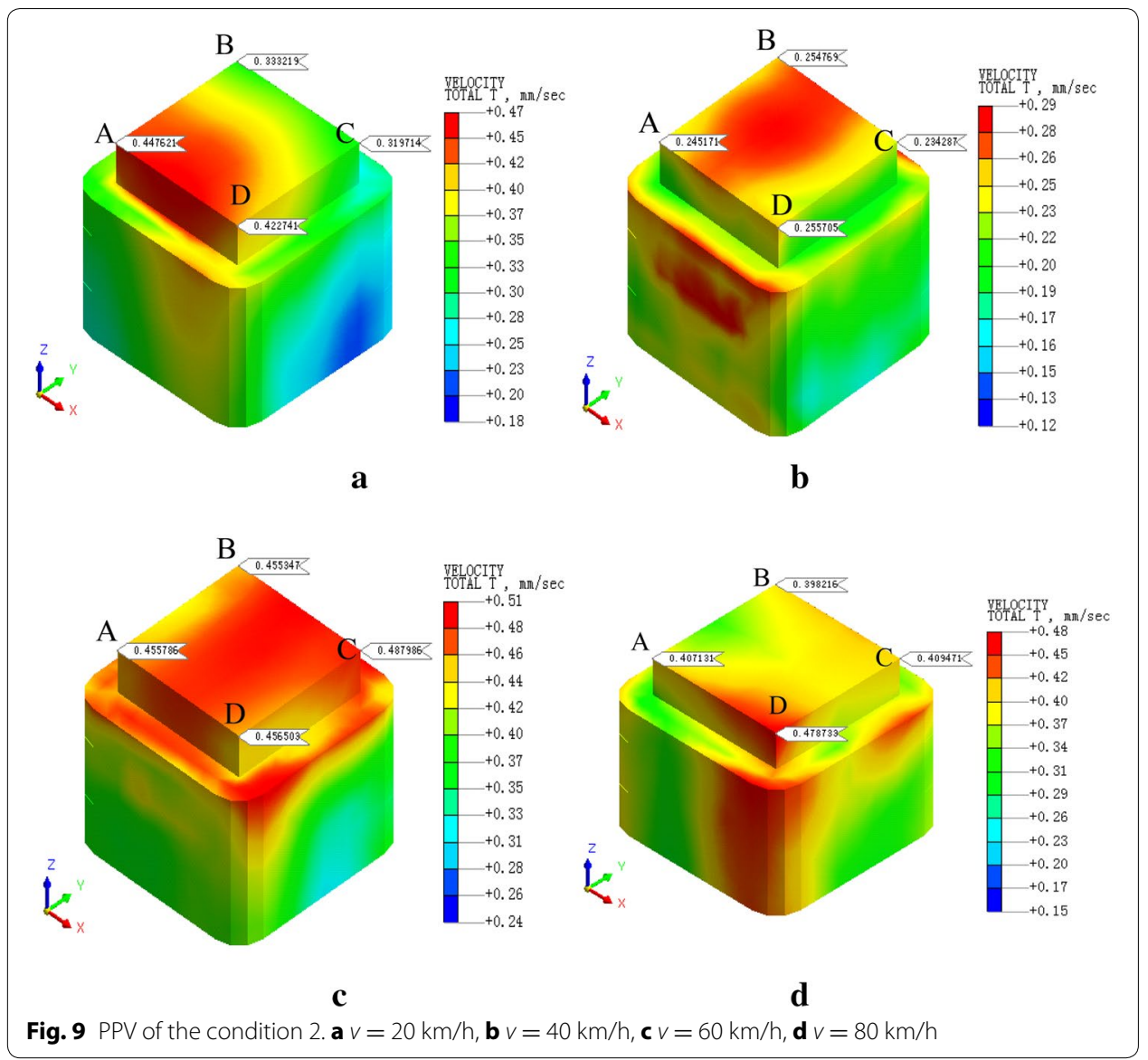

absorption tracks, the PPV of the REB beyond standard, and under the conditions 4-6 (with shock absorption tracks), the PPV was less than the allowable maximum value, which indicated that the vibration velocity of the REB was related to the track category. (3) When condition 1 (C1) versus condition 2 (C2), or $\mathrm{C} 1$ versus $\mathrm{C} 3$, or $\mathrm{C} 4$ versus $\mathrm{C}$, or $\mathrm{C} 4$ versus $\mathrm{C6}$, the PPV of four points (A, B, C and D) in four trains were large than in two trains, which indicated that the vibration velocity of the REB increase with the increase of the train quantity. (4) Comparing the condition 2 with condition 3 or condition 5 with condition 6 (Figs. 15 vs. 16, Figs. 18 vs. 19), when two trains of different routes passing through the Bell Tower at the same time, distribution laws of PPV was different with each other, which indicated that vibration velocity of the REB was related to the running mode of train.

\section{Effect of the shock absorption measures}

To evaluate the effect of the shock absorption tracks much directly, reduction of PPV was shown in Tables 7, 8 and 9. 


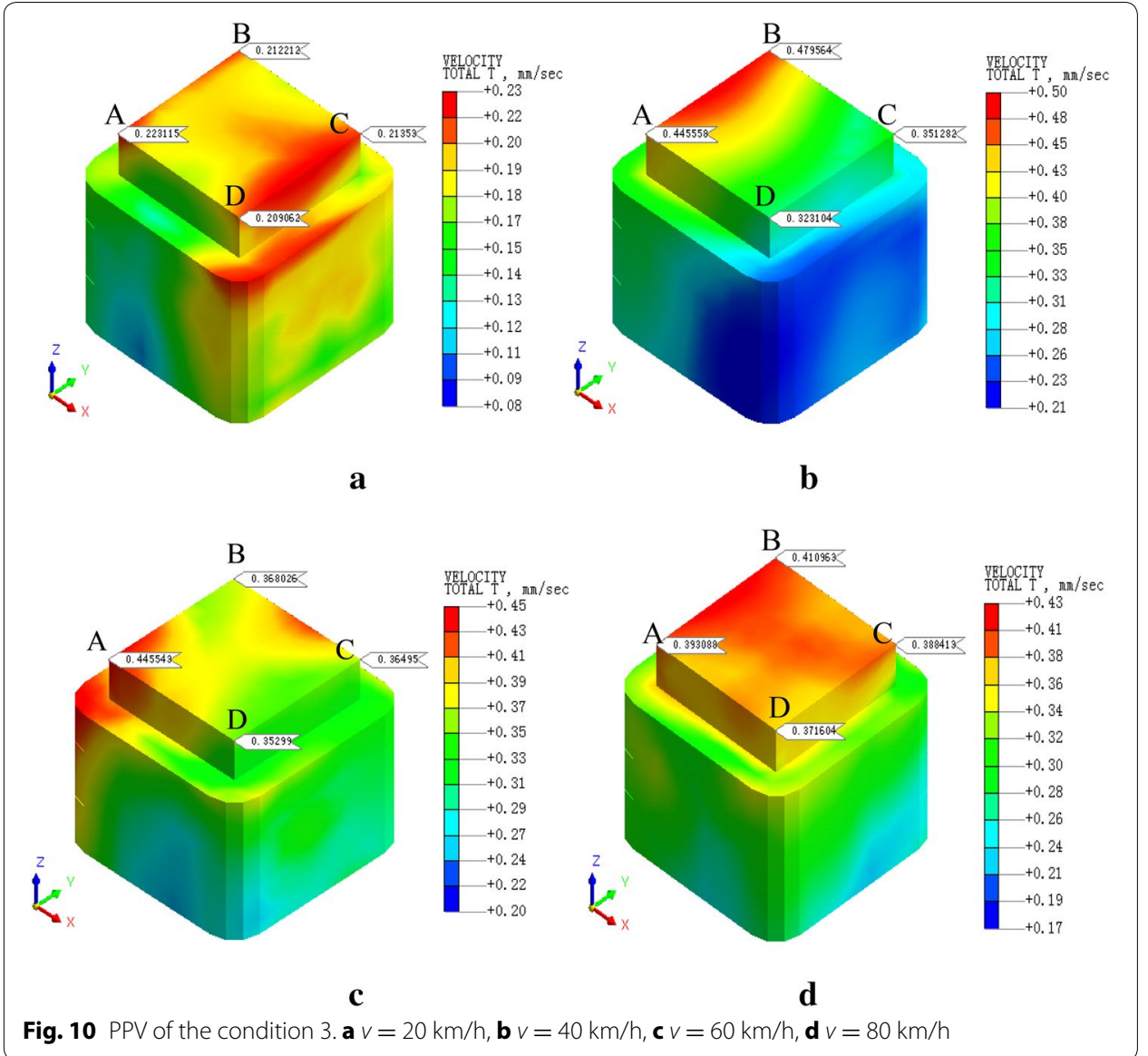

When there were no shock absorption measures, the PPV of the REB was 0.372$0.753 \mathrm{~mm} / \mathrm{s}$, beyond the standard value of $0.15-0.2 \mathrm{~mm} / \mathrm{s}$. In conditions $4-6$ with shock absorption tracks, the PPV of the REB was $0.093-0.199 \mathrm{~mm} / \mathrm{s}$, which decreased to the allowable value range. When compared with the condition 1, the PPV of four points in condition 4 reduces by $71.75-73.57 \%$. Compared with condition 2 , the PPV of four points in condition 5 reduces by $71.61-76.92 \%$. Compared with the condition 3 , the PPV of four points in condition 6 reduces $71.51-78.91 \%$. Thus, the application of shock absorption tracks can largely weaken the influence of vibration on the Bell Tower. 


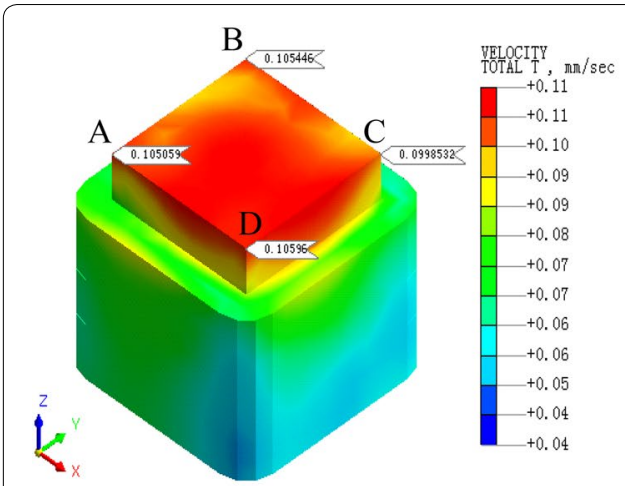

$\mathbf{a}$

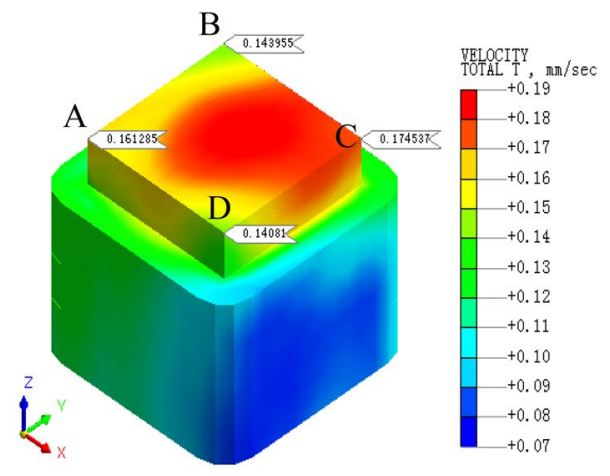

c

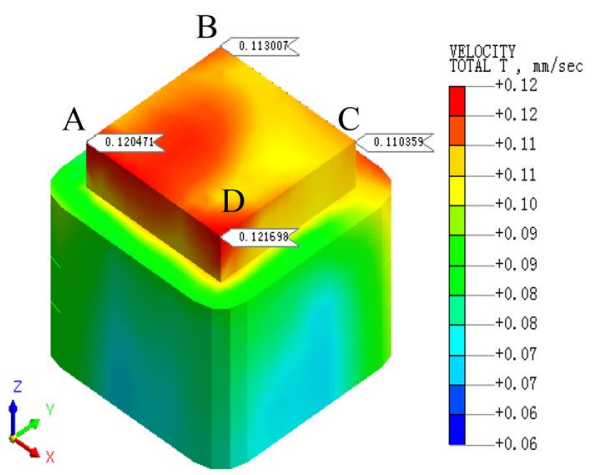

b

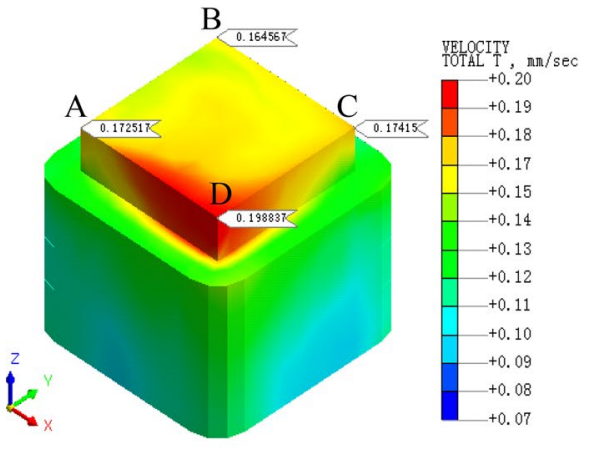

d

Fig. 11 PPV of the condition 4. a $v=20 \mathrm{~km} / \mathrm{h}, \mathbf{b} v=40 \mathrm{~km} / \mathrm{h}, \mathbf{c} v=60 \mathrm{~km} / \mathrm{h}, \mathbf{d} v=80 \mathrm{~km} / \mathrm{h}$

\section{On-site monitoring}

To validate the model, calculation results were compared with those of field tests (Ma et al. 2016). As Metro Line 6 has not been finished, this article verifies the vibration response of the Bell Tower in condition 5 when the train velocity is $60 \mathrm{~km} / \mathrm{h}$. CMG-40T sensor and REFTEK130-B intelligent signal acquisition device were applied to monitor for a period of $24 \mathrm{~h}$. According to the above analysis, the four points (A, B, C and D) is the key points, so these points were monitored (Fig. 20).

The PPV of four points under in condition 5 were consistent with field data, as shown in Table 10, which indicated that the model in this article can quantitatively reflects the actual vibration response of wooden structure. 


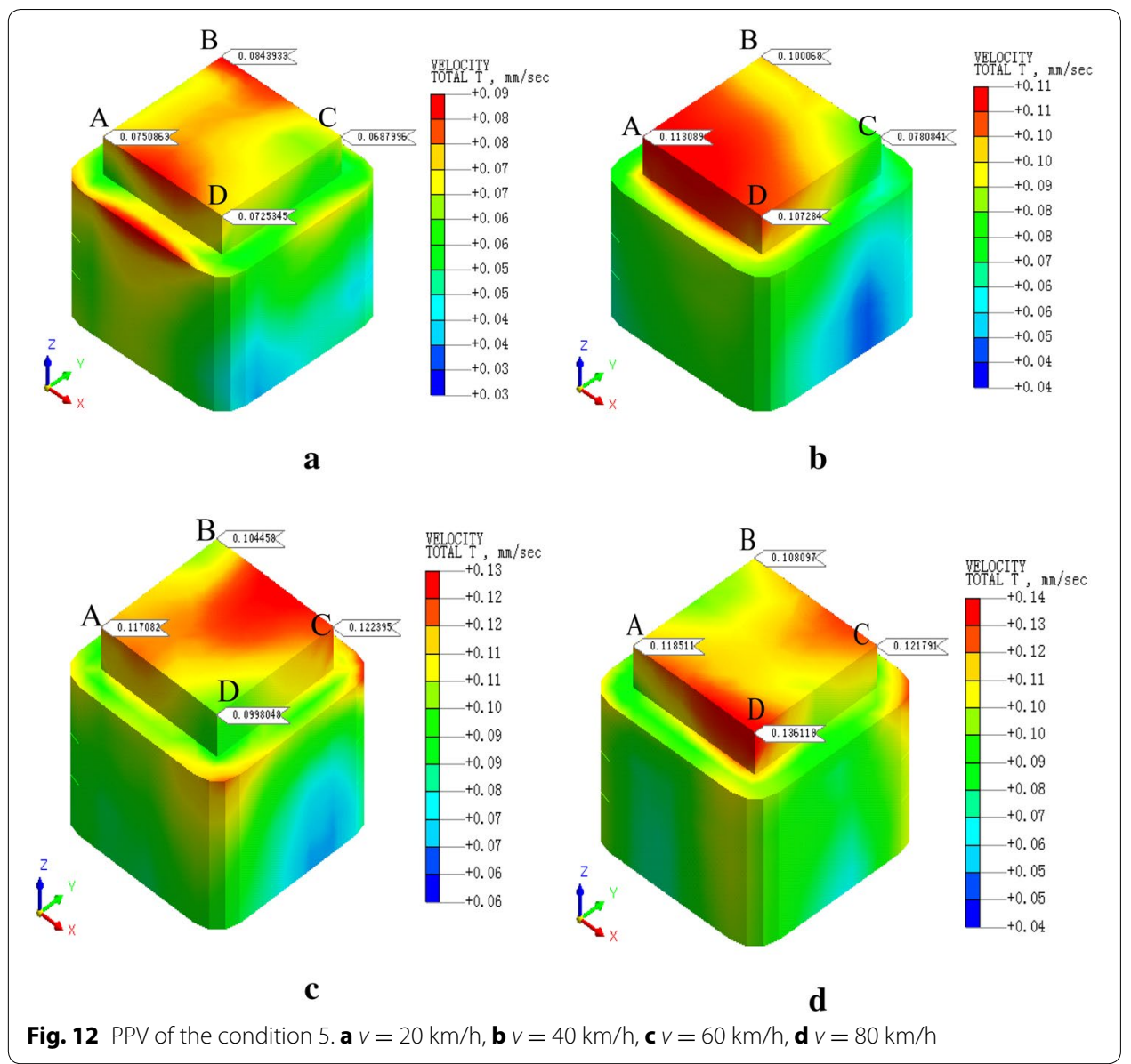

\section{Conclusions}

In order to investigate influence of vibration on ancient architectures, this article summarized vibration standards and took PPV as the safe standard for the Bell Tower. Numerical analyses were done using the MIDAS/NX in six conditions and the following results were observed:

1. The vibration velocity of the REB does not increase monotonically with the increase of the train velocity; however, it is related to the train quantity, track category and running mode of train.

2. When shock absorption tracks are not adopted, the PPV of the REB beyond the safety standard, which has the potential to induce severe damage to the Bell Tower. However, the PPV of the Bell Tower decreases greatly when vibration reduction track is adopted, and the PPV does not exceed the allowable maximum value, and the maximum decreases are $78.91 \%$. The whole predicted that the application of shock absorption tracks can weaken the influence of vibration on the Bell Tower to a great extent. 

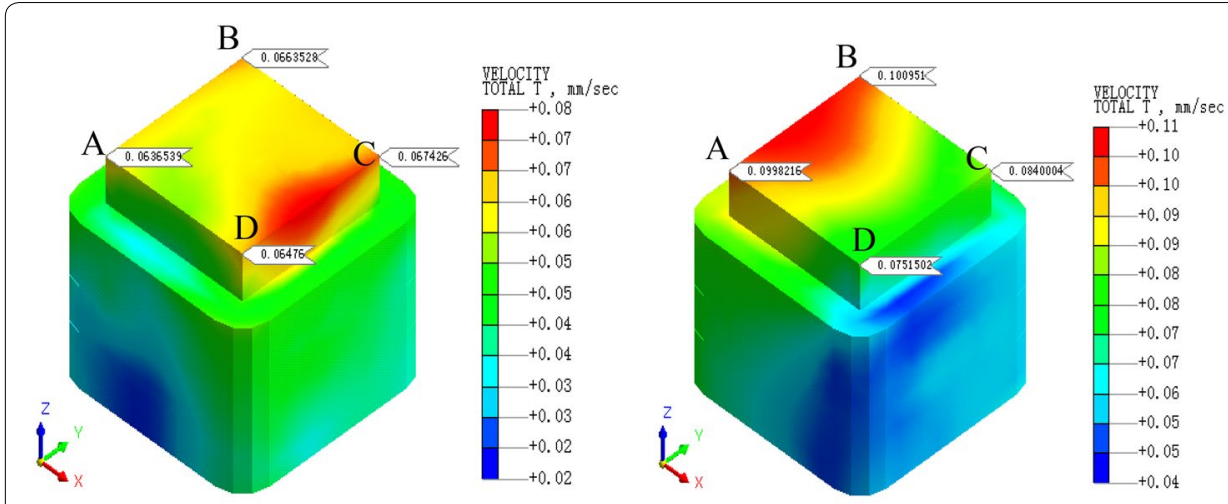

a

b
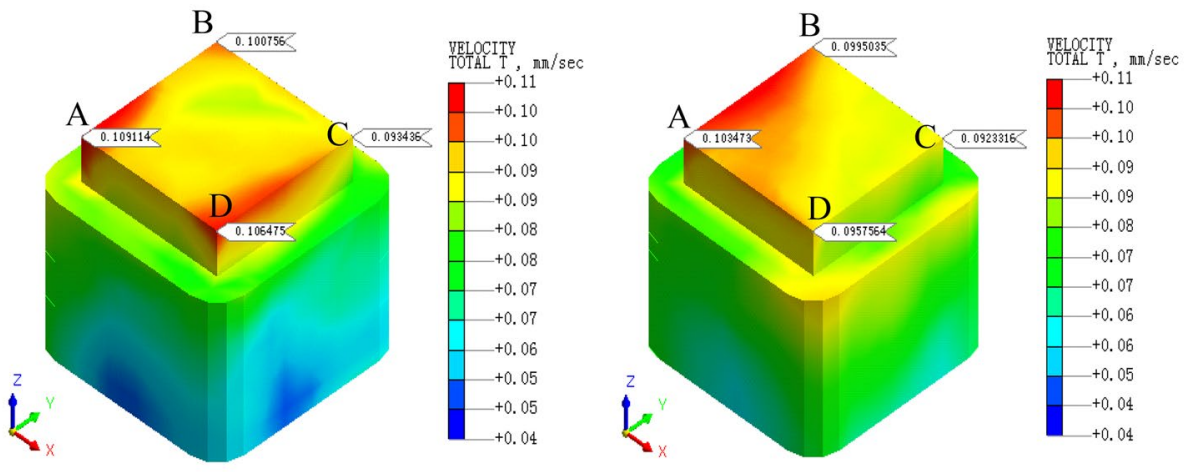

c

d

Fig. 13 PPV of the condition 6. a $v=20 \mathrm{~km} / \mathrm{h}, \mathbf{b} v=40 \mathrm{~km} / \mathrm{h}, \mathbf{c} v=60 \mathrm{~km} / \mathrm{h}, \mathbf{d} v=80 \mathrm{~km} / \mathrm{h}$

Table 5 PPV of each condition

\begin{tabular}{lllllll}
\hline Condition & $\mathbf{1}$ & $\mathbf{2}$ & $\mathbf{3}$ & $\mathbf{4}$ & $\mathbf{5}$ & $\mathbf{6}$ \\
\hline PPV & 0.752 & 0.488 & 0.479 & 0.199 & 0.136 & 0.109 \\
Train velocity & 80 & 60 & 40 & 80 & 80 & 60 \\
The max location & D & C & B & D & D & A \\
Figures & Figure 8d & Figure 9c & Figure 10b & Figure 11d & Figure 12d & Figure 13c \\
\hline
\end{tabular}

Table 6 PPV of each condition

\begin{tabular}{lllllll}
\hline Condition & $\mathbf{1}$ & $\mathbf{4}$ & $\mathbf{2}$ & $\mathbf{5}$ & $\mathbf{3}$ & $\mathbf{6}$ \\
\hline 20 & D & D & A & A & A & C \\
40 & C & D & D & A & B & B \\
60 & C & C & C & C & A & A \\
80 & D & D & D & D & B & A \\
\hline
\end{tabular}




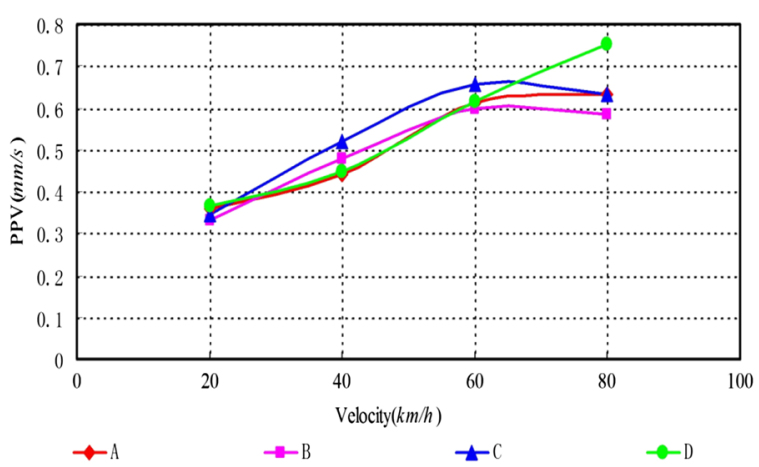

Fig. 14 Condition 1

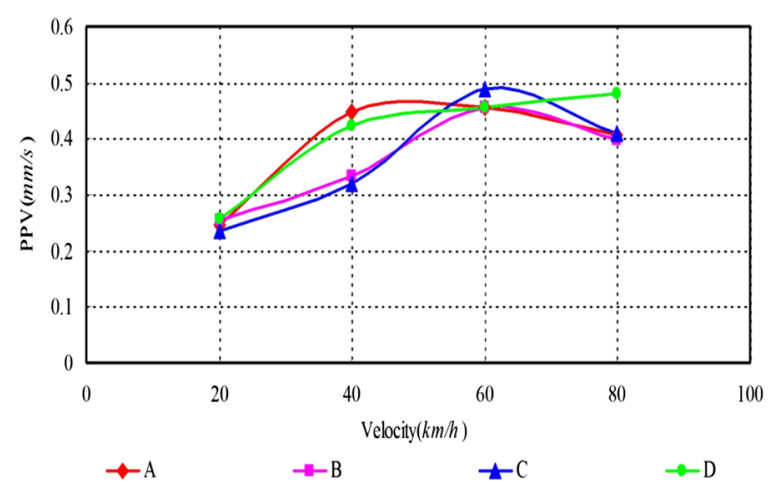

Fig. 15 Condition 2

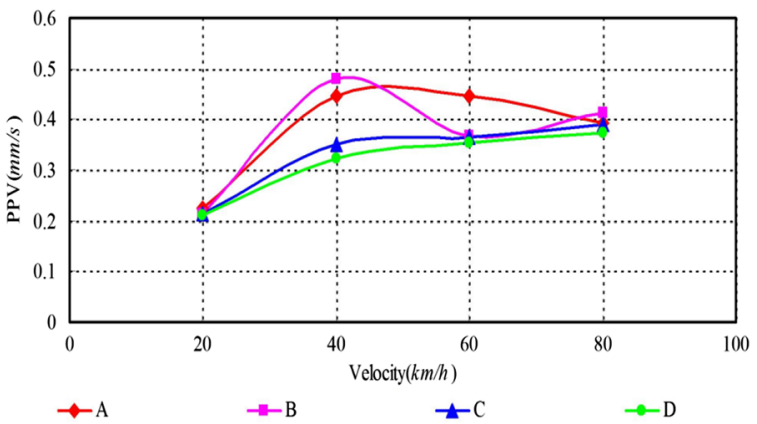

Fig. 16 Condition 3 


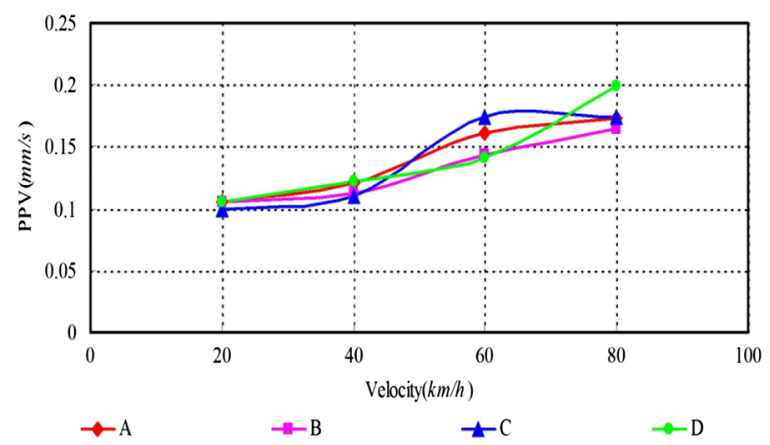

Fig. 17 Condition 4

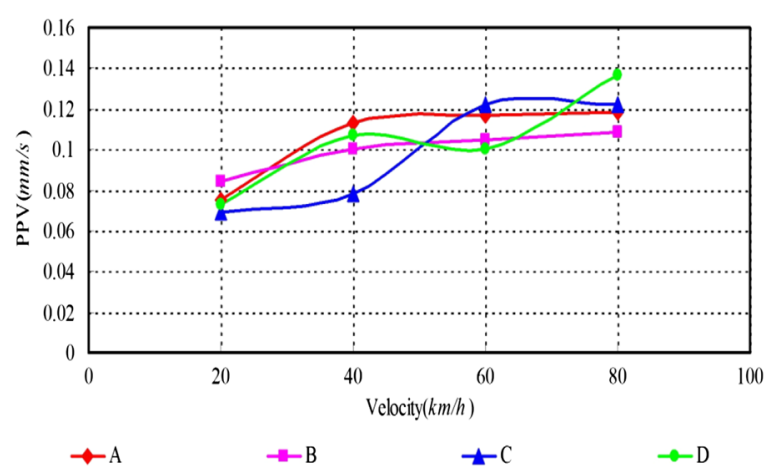

Fig. 18 Condition 5

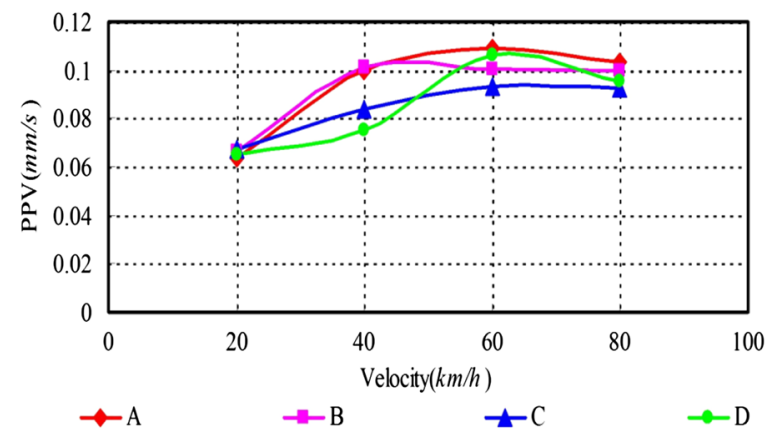

Fig. 19 Condition 6

Table 7 Condition 1 versus condition 4

\begin{tabular}{lcccc}
\hline Point & A (mm/s) & B (mm/s) & C (mm/s) & D (mm/s) \\
\hline Condition 1 & 0.634 & 0.584 & 0.655 & 0.753 \\
Condition 4 & 0.172 & 0.165 & 0.175 & 0.199 \\
$\mathrm{R}(\%)$ & 72.87 & 71.75 & 73.28 & 73.57 \\
\hline
\end{tabular}


Table 8 Condition 2 versus condition 5

\begin{tabular}{lcclc}
\hline Point & A ( $\mathbf{m m} / \mathbf{s})$ & $\mathbf{B}(\mathbf{m m} / \mathbf{s})$ & $\mathbf{C}(\mathbf{m m} / \mathbf{s})$ & $\mathbf{D}(\mathbf{m m} / \mathbf{s})$ \\
\hline Condition 2 & 0.455 & 0.455 & 0.488 & 0.479 \\
Condition 5 & 0.117 & 0.108 & 0.122 & 0.136 \\
R (\%) & 74.29 & 76.92 & 75 & 71.61 \\
\hline
\end{tabular}

Table 9 Condition 3 versus condition 6

\begin{tabular}{lcccc}
\hline Point & A (mm/s) & B ( $\mathbf{m m} / \mathbf{s})$ & C (mm/s) & D (mm/s) \\
\hline Condition 3 & 0.445 & 0.479 & 0.388 & 0.372 \\
Condition 6 & 0.109 & 0.101 & 0.093 & 0.106 \\
R (\%) & 75.51 & 78.91 & 76.04 & 71.51 \\
\hline
\end{tabular}

$R=\frac{\left(P_{1}-P_{2}\right)}{P_{1}}$, where $\mathrm{R}$ is reduction, $\mathrm{P} 1$ is $\mathrm{PPV}$ with shock absorption tracks, and $\mathrm{P} 2$ is PPV without shock absorption tracks
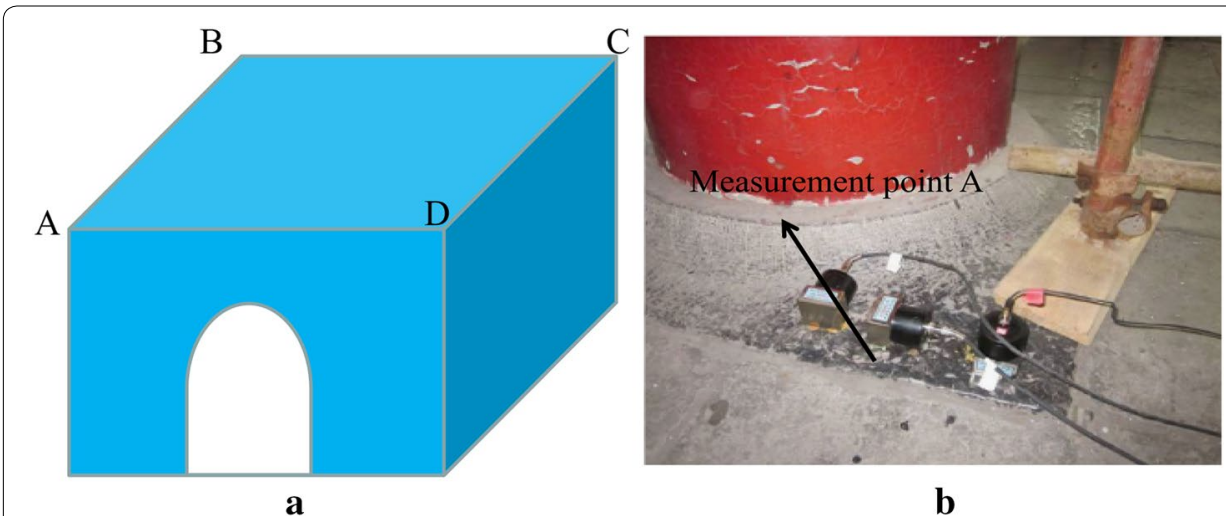

b

Fig. 20 On-site monitoring. a Sketch of measurement points, b measurement point A (Ma et al. 2016)

\section{Table 10 On-site versus calculation results}

\begin{tabular}{lll}
\hline Point & On-site $(\mathrm{mm} / \mathbf{s})$ & Model $(\mathrm{mm} / \mathbf{s})$ \\
\hline A & 0.125 & 0.117 \\
B & 0.133 & 0.108 \\
C & 0.148 & 0.122 \\
D & 0.153 & 0.136 \\
\hline
\end{tabular}

3. After the verification on calculation result for the model in this article through onsite monitor, it is discovered that the model can quantitatively reflect the actual vibration response of the Bell Tower. Therefore, we will investigate the settlement of REB and the PPV of the wooden structure caused by vibration for the Bell Tower in the following study.

Authors' contributions

JXL established the analytical approach. FYN and KW performed the numerical analysis and wrote the manuscript. JXC, $J \mathrm{LQ}, \mathrm{HBF}$ and $\mathrm{ZNH}$ compared the calculation results. All the authors read and approved the final manuscript. 


\begin{abstract}
Author details
${ }^{1}$ School of Highway, Chang'an University, Xi'an 710064, China. ${ }^{2}$ China Railway First Survey and Design Institute Group Co., Ltd., Xi'an 710043, Shaanxi, China. ${ }^{3}$ School of Civil Engineering, Shijiazhuang Tiedao University, Shijiazhuang 050043, China.
\end{abstract}

\title{
Acknowledgements
}

This work is financially supported by the Special Fund for Basic Scientific Research of Central Colleges of Chang'an University (Grant No. 310821165011), the Integrated Innovation Project of Shaanxi Provincial Science and Technology Department (Grant No. 2015KTZDGY01-05-02) and the Brainstorm Project on Social Development of Shaanxi Provincial Science and Technology Department (Grant No. 2016SF-412).

\section{Competing interests}

The authors declare that they have no competing interests.

Received: 3 March 2016 Accepted: 20 June 2016

Published online: 30 June 2016

\section{References}

BS7385-2 (1993) Evaluation and measurement for vibration in buildings_-part 1. In: Guide for measurement of vibrations and evaluation of their effects on buildings

Cao YM (2006) Vibration of high-rise buildings induced by running trains. Eng Mech 23(3):162-167

Chen RC (2008) Study on effects on Bell Tower due to train-induced vibrations on metro in Xi'an. Ph.D. Thesis, Beijing Jiaotong University

Clemente P, Rinaldis D (1998) Protection of a monumental building against traffic induced vibrations. Soil Dyn Eartha Eng 17(5):289-296

Dawn TM, Stanworth CG (1979) Ground vibration from passing trains. J Sound Vib 66(2):355-362

Degrande G, De Roeck G (1998) Wave propagation in layered dry, saturated and unsaturated pore elastic media. Solid Struct 35(34-35):4753-4778

Degrande G, Lombaert G (2001) An efficient formulation of Krylov's prediction model for train induced vibrations based on the dynamic reciprocity theorem. J Acoust Soc Am 110(3):1379-1390

DIN4150-3 (1999) Structural vibration Part3. In: Effect of vibration on structures

Ellis P (1987) Effect of traffic vibration on historic buildings. Sci Total Environ 59:37-45

GB/50894 (2003) Code for design of environment protection for machinery industry. China Machine Press, Beijing

GB/T50452 (2008) Technical specification for protection of historic buildings against man-made vibration. China Machine Press, Beijing

Han XH, Jia WL (2015) Study on the effect and mechanism of aerodynamic measures for the vortex-induced vibration of separate pairs of box girders in cable-stayed bridges. Shock Vib. doi:10.1155/2015/792957

Han WS, Yuan SJ, Ma L (2014) Vibration of vehicle-bridge coupling system with measured correlated road surface roughness. Struct Eng Mech. doi:10.12989/sem.2014.51.2.315

ISO 4866 (2010) Mechanical vibration and shock-vibration of fixed structures-guidelines for the measurement of vibrations and evaluation of their effects on structures

Jia YX, Guo M, Liu WN et al (2009) Dynamic effect of train induced vibration on historic buildings. J Beijing Jiaotong Univ 33(1):118-122

Kurzweil G (1979) Ground borne noise and vibration from underground rail systems. J Sound Vib 66(3):363-370

Lai HP, Wang SY, Xie YL (2014) Experimental research on temperature field and structure performance under different lining water contents in road tunnel fire. Tunn Undergr Space Technol 43:327-335

Lai JX, Fan HB, Chen JX et al (2015a) Blasting vibration monitoring of under crossing railway tunnel using wireless sensor network. Int J Distrib Sens Netw, Article ID 703980, 7 pages. doi:10.1155/2015/703980

Lai JX, Qiu JL, Chen JX et al (2015b) New technology and experimental study on snow-melting heated pavement system in tunnel portal. Adv Mater Sci Eng, Article ID 706536, 11 pages. doi:10.1155/2015/706536

Lai JX, Mao S, Qiu JL et al (2016a) Investigation progresses and applications of fractional derivative model in geotechnical engineering. Math Probl Eng, Article ID 9183296, 15 pages. doi:10.1155/2016/9183296

Lai JX, Qiu JL, Feng ZH et al (2016b) Prediction of soil deformation in tunnelling using artificial neural networks. Comput Intell Neurosci, Article ID 6708183, 16 pages. doi:10.1155/2016/6708183

Lai JX, Wang KY, Qiu JL et al (2016c) Vibration response characteristics of the cross tunnel structure. Shock Vib, Article ID 9524206, 11 pages. http://www.hindawi.com/journals/sv/aip/9524206/. Accessed 28 June 2016

Lang J (1971) Result of measurements on the control of structure-borne noise from subways. In: Seventh international congress on acoustics, Budapest, pp 421-424

Li JC, Li HB, Ma GW et al (2013) Assessment of underground tunnel stability to adjacent tunnel explosion. Tunn Undergr Space Technol 35:227-234

Lombaert G, Degrande G, Kogut J (2006) The experimental validation of a numerical model for the prediction of railway induced vibrations. J Sound Vib 297(3-5):512-535

Luo G, Chen JX, Zhou XJ (2015) Effects of various factors on the VIV-induced fatigue damage in the cable of submerged floating tunnel. Pol Marit Res 4(88):76-83

Ma M, Liu W, Qian CY, Deng GH, Li YD (2016) Study of the train-induced vibration Impact on a historic Bell Tower above two spatially overlapping metro lines. Soil Dyn Eartha Eng 81:58-74

Mata M (1971) Effects on buildings of vibrations caused by traffic. Build Sci 6:221-246 
Meng ZB (2009) Analysis and assessment of the vibration responds traffic-induced of Xi'an Bell Tower, Ph.D. Thesis, Xi'an University of Architecture and Technology

MIDAS Co. Ltd. MIDAS/NX manual. http://manual.midasuser.com/encommon/GTS\%20NX/250/GTX.htm

Real J (2014) Computational considerations of 3-D finite element method models of railway vibration prediction in ballasted tracks. JVibroeng 16(4):1709-1722

Real T, Zamorano C, Ribes F (2015) Train-induced vibration prediction in tunnels using 2D and 3D FEM models in time domain. Tunn Undergr Space Technol 49:376-383

RuekerW (1982) Dynamic behavior of rigid foundations of arbitrary shape on a half-space. Earthq Eng Struct Dyn 66(5):674-690

Swiss Association of Standards (1992) Effects of vibration on construction, SN 640312, CH8008, Zurich

Xie DW (2008) Evaluation report of vibration influence to historic and sensitive buildings along Beijing Subway Line8, Ph.D. Thesis, Beijing Jiaotong University

Ye F, Gou CF, Sun HD et al (2014) Model test study on effective ratio of segment transverse bending rigidity of shield tunnel. Tunn Undergr Space Technol 41:193-205

Ye M, Cao BX, Ren YP et al (2015) Field measurement, analysis and protection for the vibration of an ancient ruin induced by railway. J Vibroeng 17(4):2049-2065

Yu MH, Fang DP (2006) Advances in structural mechanics of Chinese ancient architectures. Adv Mech 36(1):43-64

Zhao HB, Long Y, Ji C et al (2015) Study on the dynamic response of subway tunnel by viaduct collapsing vibration and the protective measures of reducing vibration. J Vibroeng 17(5):2433-2443

\section{Submit your manuscript to a SpringerOpen ${ }^{\circ}$ journal and benefit from:}

- Convenient online submission

\section{- Rigorous peer review}

- Immediate publication on acceptance

- Open access: articles freely available online

- High visibility within the field

Retaining the copyright to your article

Submit your next manuscript at $\boldsymbol{s p r i n g e r o p e n . c o m ~}$ 